\title{
Knowledge and Attitude of Medical and Dental Postgraduate Students toward Practice of Biostatistics
}

\author{
${ }^{1}$ Medha Wadhwa, ${ }^{2}$ Pulkit Kalyan, ${ }^{3}$ Thanveer Kalantharakath
}

\begin{abstract}
Purpose: Evidence-based medicine (EBM) has appropriately focused attention on critical appraisal of clinical research. A result of this movement is that medical specialists must improve their grasp of epidemiological and statistical principles. This process necessitates a substantial level of expertise of the reader to appraise the design, methodology, data analysis, and interpretation of findings of relevant studies to arrive at conclusions. The foregoing requirements, together with the progressively increasing complexity of statistical methods, make information processing a complex task. This 'gap' between health science researchers and the understanding of mathematics and the statistical methods could justify the disinterest of a considerable part of clinical researchers and postgraduate students.
\end{abstract}

Materials and methods: A cross-sectional and descriptive study was conducted on all the enrolled medical and dental postgraduate students of 3 years belonging to the Sumandeep Vidyapeeth. The study subjects were distributed questionnaire that consisted of 2 parts which had questions related to the attitude and knowledge regarding the practice of biostatistics among the study subjects.

Results: The level of knowledge among the postgraduates was moderate and the attitude was found to be highly positive. Significant results were obtained that showed that the knowledge and attitude toward practice of biostatistics are strongly associated with each other with correlation coefficient to be 0.82 .

Conclusion: The knowledge and attitude of medical and dental postgraduate students was found to be highly correlated indicating that with higher level of attitude increased knowledge can be acquired for practice of biostatistics among them. Biostatistics is perceived as an important element of EBM and incorporating it into EBM practice and curriculum would pave new ways into research field.

Keywords: Knowledge, Attitude, Biostatistics, Practice, Postgraduate students.

How to cite this article: Wadhwa M, Kalyan P, Kalantharakath T. Knowledge and Attitude of Medical and Dental Postgraduate

\footnotetext{
${ }^{1}$ Assistant Professor, ${ }^{2}$ Senior Lecturer, ${ }^{3}$ Professor

${ }^{1}$ Department of Healthcare Management, Sumandeep Vidyapeeth University, Vadodara, Gujarat, India

2,3Department of Public Health Dentistry, Sumandeep Vidyapeeth University, Vadodara, Gujarat, India
}

Corresponding Author: Medha Wadhwa, Assistant Professor Department of Healthcare Management, Sumandeep Vidyapeeth University, Vadodara, Gujarat, India, Phone: 9537624644, e-mail: drmedhakalyan@gmail.com
Students toward Practice of Biostatistics. J Postgrad Med Edu Res 2015;49(1):1-4.

Source of support: Nil

Conflict of interest: None

\section{INTRODUCTION}

Pierre-Charles-Alexander Louis, WilliaFarr and John Snow were the first who introduced and applied the statistical methods in medical research. ${ }^{1}$ Statistics is mainly used in biological research to verify the clinicians and researchers findings and feelings, and gives scientific validity for their inferences. It is very difficult for a medical professional to understand the statistical concepts. However, it is important that clinicians involved with researches to understand the fundamental statistical issues in order to uphold the integrity of a research and is also seen to be an important factor for reading and understanding medical journals. ${ }^{2}$

As a matter of fact, the concept of evidence-based medicine (EBM) has been promoted as a new paradigm for medical education. This exercise was designed as a limited but feasible intervention which would build on earlier learning from the preclinical, clinical epidemiology and biostatistics courses and demonstrate an approach that students could practice during clinical years. For this reason, it is essential that errors in scientific articles must be minimized as much as possible.

A great increase in the use of statistics has been observed over the past decades in medical Journals. Nevertheless, according to a study published on The American statistician on February 2007, 'a high proportion of published medical research contains statistical errors' ${ }^{3}$

There are several common statistical concerns in clinical researches including poor $\mathrm{p}$-value interpretation, the need for presenting confidence intervals, adherence to the intent-to-treat principle, missing data, multiplicity, subgroup analyses, and association vs causation, appropriate reporting of trial results, probability and Bayesian statistics, and the clinician-statistician interaction and the importance of effective communication. ${ }^{4}$

Students generally agree that understanding clinical statistics is critical for intelligent interpretation of the clinical literature. However, because of time constraints and inadequate statistics background, clinicians rely 
on numerous short cuts (such as reading abstracts, and opinion pieces) to remain current. ${ }^{5}$

The objective of the present study is: To assess the level of knowledge and attitude toward practice of biostatistics among the dental and medical postgraduate students at Sumandeep Vidyapeeth, Vadodara and to assess the level of correlation between knowledge and attitude.

Rationale of the current study includes the following:

1. The growing need to effectively interpret results for patients as clinical decisions become more complex.

2. The expanding role of consumers of the medical literature as 'judges of experimental design, statistics, and analysis' as the number of outlets for research reporting increases beyond our ability to properly provide comprehensive peer review.

3. Limitations in access to epidemiological and statistical experts when help is required.

Although the need for improved education in medical statistics is clear, the fact that assessments of statistical knowledge of clinicians have shown little change during the past several decades suggests little is known about how to accomplish such improvement. Understanding current perceptions held by postgraduates of medical and dental colleges regarding statistics and its role in both research and clinical practice may be helpful in improving teaching on this subject.

\section{MATERIALS AND METHODS}

A cross-sectional, descriptive questionnaire survey was conducted on 458 postgraduate students of medical and dental college of Sumandeep Vidyapeeth, Piparia, Vadodara, Gujarat. The study protocol was reviewed and approved by the research cell of KM Shah Dental College and Hospital, i.e. Human Research Review Board and ethical approval was obtained by the Ethics committee, Sumandeep Vidyapeeth, Piparia, Vadodara.

The study subjects were all the enrolled postgraduate students of 3 years of medical and dental college at Sumandeep Vidyapeeth, Piparia, Vadodara. Questionnaire was prepared by referring the available literature. Expert opinions for content validity were obtained from the biostatistics head of the institution. The results of the questionnaire were used to check the internal consistency. The value for cronbach's alpha is 0.65 . The questionnaire consisted of two parts; first part consisted of the demographic profile and the second part had questions related to attitude and knowledge of students. It was distributed to all the postgraduate students. The response rate was found to be $93.44 \%$. Out of 458,428 students were found to be valid and were included for analysis.

\section{Inclusion Criteria}

All the medical and dental postgraduate students (Ist, IInd, IIIrd year) at respective colleges of Sumandeep Vidyapeeth.

\section{Exclusion Criteria}

Incomplete questionnaire and the students who did not return the questionnaire were excluded.

\section{STATISTICAL METHOD}

The data were compiled and were entered into Microsoft Excel sheet and then was analyzed using SPSS 20.0 version for windows. Descriptive statistics was calculated using cross-tabulation, means and standard deviations. The Pearson's correlation coefficient was used to calculate the correlation among knowledge and attitude and the year of post graduation. The $\mathrm{p}$-value was set at 0.05 for analyzing the level of significance.

\section{RESULTS}

Among the 428 study groups included in the study, $75.2 \%$ were male and $24.8 \%$ were female. As shown in Table 1, Majority of the participants had high level $(80 \%)$ of attitude toward biostatistics. $93.5 \%$ of respondents believed that statistics is the worthwhile part of their career. While it was observed that almost $73.6 \%$ respondents believed that statistics help them to understand research in their specialty.

Table 2 shows the percentage of respondents who gave correct responses the questions to assess the level of knowledge among the postgraduates. It can be seen that postgraduates have a moderate level of knowledge in biostatistics in all the questions except in the question regarding the classification of data for categorizing the type of birth where the level of knowledge is seen to be low $(56.35 \%)$.

Table 3 depicts highly significant correlation between knowledge and attitude with Pearson's correlation coefficient value to be 0.82 . This indicates that postgraduates showing high attitude toward practice of biostatistics was associated with high level of knowledge on the subject.

Table 1: Percentage distribution of respondents toward attitude statements

\begin{tabular}{|c|c|c|c|}
\hline & Statements & Yes (\%) & No (\%) \\
\hline 1. & $\begin{array}{l}\text { Statistics is a worthwhile part of my area } \\
\text { of study }\end{array}$ & 93.5 & 6.5 \\
\hline 2. & Statistics is too math-oriented & 76.63 & 23.37 \\
\hline 3. & $\begin{array}{l}\text { To read scientific literature is necessary } \\
\text { to have knowledge of biostatistics }\end{array}$ & 81.77 & 18.23 \\
\hline 4. & $\begin{array}{l}\text { Statistics helps me to understand } \\
\text { research in my specialty }\end{array}$ & 73.6 & 26.4 \\
\hline
\end{tabular}


From Tables 1 to 3, it can be concluded that the post graduate students of medical and dental college at Sumandeep Vidyapeeth showed a high level of attitude and moderate knowledge but the correlation between them was found to be highly significant suggesting that with high level of attitude, increased efforts can lead to a higher level of knowledge among them.

\section{DISCUSSION}

It is essential for physicians, both in clinical practice and research, to be able to judge the quality of research reported in journals to stay up-to-date in their profession. A clear understanding of the basic principles of biostatistics is required to achieve this goal. Butt and $\mathrm{Khan}^{5}$ found that in a critical review of over 4000 research studies, only $20 \%$ of those reviewed had correct study design, data collection and statistical methods. Although this was reported 2 decades ago, the problem persists and is the result of inadequate focus on biostatistics given during undergraduate and postgraduate years.

In the present study, the medical and dental postgraduate students the attitude regarding the practice of biostatistics was high. $76.63 \%$ of the respondents believed statistics to be too math oriented but at the same time $81.77 \%$ felt that it is necessary to have knowledge of biostatistics to read scientific literature. Khan and

Table 2: Percentage of correct response among the respondents showing their level of knowledge

\begin{tabular}{|c|c|}
\hline Questions & $\begin{array}{l}\text { Percentage } \\
\text { of correct } \\
\text { response } \\
(\%)\end{array}$ \\
\hline Weight at birth in grams (A) & 78.41 \\
\hline Weight classified as low, medium, high (B) & 72.57 \\
\hline $\begin{array}{l}\text { Type classified as cesarean birth, natural or } \\
\text { induced (B) }\end{array}$ & 56.35 \\
\hline $\begin{array}{l}\text { To evaluate the effectiveness of two fruit juices } \\
\text { on dissolvability of kidney stones among patients } \\
\text { attending the outpatient department of Dhiraj } \\
\text { hospital (B) }\end{array}$ & 68.92 \\
\hline The purpose of a double-blind trial is $(C)$ & 68.58 \\
\hline $\begin{array}{l}\text { Comparison of mean between two variables when } \\
\text { the normal distribution can be compared by }(A)\end{array}$ & 69.65 \\
\hline $\begin{array}{l}\text { Final result of the study is accurate when the } \\
\text { sample drawn is (C) }\end{array}$ & 65.42 \\
\hline $\begin{array}{l}\text { A researcher divides the population into certain } \\
\text { groups and fixes the size of the sample from each } \\
\text { group (D) }\end{array}$ & 74.9 \\
\hline
\end{tabular}

Table 3: Correlation between attitude and knowledge of biostatistics

\begin{tabular}{lll}
\hline & Correlation coefficient & $p$-value \\
\hline $\begin{array}{l}\text { Attitude and } \\
\text { knowledge }\end{array}$ & 0.82 & $0.002^{*}$ (highly significant) \\
\hline${ }^{*}$ p-value $<0.05$ &
\end{tabular}

Mumtaz ${ }^{2}$ concluded that about $80 \%$ of medical faculty showed interest in the questions, related to statistical training. ${ }^{6,7}$

Polychronopoulou et al and Horton and Switzer ${ }^{8,9}$ in their survey concluded that advanced statistical tests, such as Cox proportional hazard regression, were difficult to correctly identify by most of the participants. Windish et $\mathrm{al}^{7}$ concluded in an American report almost $75 \%$ of the respondents admitted not having full knowledge of all statistical procedures reported in medical journals.

The present study has shown highly significant correlation of 0.82 between attitude and knowledge toward biostatistics. In this study, a moderate level of knowledge among the study subjects was seen. The highest percentage of correct response was seen in the question regarding identification of the scale of the data but the same technique when asked in a different question had the lowest percentage of $56.35 \%$ among the respondents. This indicates unclear understanding on topic related to scaling technique. $69.65 \%$ of the respondents were able to identify the appropriate test for comparison of means. It was also seen that purpose of sampling and the appropriate technique was clear to the respondents.

After conducting the present study and evaluating the results it can be recommended that both using pedagogical tools which are unique and innovative may help the students to develop a positive attitude toward the subject. Also, it is recommended that the concerned senior faculties should pay timely attention to these characteristics and provide adequate interventions to improve the same. Future studies should consider developing and testing interventions to develop positive attitude toward biostatistics. Instead of self reporting questionnaires, a strong design, such as in-depth qualitative study would be more accurate and informative.

Biostatistics is perceived as an important element of EBM, and successful efforts to teach biostatistics may benefit from incorporating statistical concepts into EBM teaching frameworks already in place.

\section{ACKNOWLEDGMENTS}

It gives us immense pleasure to express my heartfelt gratitude to my guide Dr Md Mahtab Alam, who with his persistent quest for perfection and patience, extended his support, guidance with priceless suggestions and encouragement right through this study. I am indebted to him.

We are grateful to Dr Thanveer K (Professor and HOD) and Dr Ajith Krishnan CG (Principal) whose knowledge, experience, clear judgment and generous cooperation helped me in accomplishing our task. 


\section{REFERENCES}

1. Patel S, Patel P, Bansal RK. Some basic application of biostatistics in biomedical research. National J Comm Med 2012;3(4): 748-749.

2. Khan N, Mumtaz Y. Attitude of teaching faculty towards statistics at a medical university in Karachi, Pakistan. J Ayub Med Coll Abbottabad 2009;21(3):166-171.

3. Araújo AC, Mesquita AM. Medical students perspective on the teaching of medical statistics in the undergraduate medical curriculum. Stat Med 2010;21(7):1003-1006.

4. Evans SR. Common statistical concerns in clinical trials. J Exp Stroke Transl Med 2010 Feb;3(1):1-7.
5. Butt AK, Khan AA. Teaching biostatistics and epidemiology in a postgraduate medical institution: are we going in right direction. Eastern Mediterranean Health J 2008;14(5):1192-1197.

6. West CP, Ficalero RD. Clinician attitude towards biostatistics. Mayo Clin Proc 2007;82(8):939-943.

7. Windish DM, Huot SJ, Green ML. Medicine residents understanding of the biostatistics and results in the medical literature. J Am Med Assoc 2007;298(9):1010-1022.

8. Polychronopoulou A, Eliades T, Toufik K, et al. Knowledge of European orthodontic postgraduate students on biostatistics. Eur J Orthod 2011 Aug;33(4):434-440.

9. Horton NJ, Switzer SS. Statistical methods in the journal. N Engl J Med 2005 Nov;353(18):1977-1979. 